Jonas DUNTSCHEW ${ }^{1 *}$

Sarah ESCHELBACHER ${ }^{1}$

Ivo SCHLUCHTER ${ }^{1}$

Hans-Christian MÖHRING ${ }^{1}$

\title{
DISCRETE WAVELET TRANSFORMATION AS A TOOL FOR ANALYSING THE BOREHOLE QUALITY WHEN DRILLING CARBON FIBRE REINFORCED PLASTIC ALUMINIUM STACK MATERIAL
}

\begin{abstract}
To meet the higher demands of the lightweight industry, composite materials are used for weight-bearing structures. Due to their superior properties, CFRP (Carbon Fibre Reinforced Plastic) - aluminium stacks are especially attractive for many applications in the aerospace industry. Using rivets to connect these materials requires precise boreholes in large numbers, which are usually drilled. Because of the anisotropic material properties, high demands on the tool performance and process stability are set. Damages such as delamination, fibre pull-outs and inadequate surface properties are frequently observed at the drilled boreholes. To improve the monitoring status and failure detection, acoustic emission during drilling was analysed using the discrete wavelet transform method. By converting time signals into multiple independent time-frequency signals, temporary events during the monitoring of the cutting processes can be found. The studies show that certain combinations of wavelet families are particularly useful for describing correlations between acoustic emission and the delamination of the CFRP surface.
\end{abstract}

\section{INTRODUCTION}

Facing a steadily increasing demand for lightweight design in the aircraft industry, multimaterials are being used in addition to CFRP. Aircrafts such as the Airbus A350, MS21, the Boeing 787 or the Bombardier C Series use structure components made out of stacks. Stack materials are characterized by great bending strength, tensile strength and fatigue resistance with low density.

Riveting is a joining technique used widely in the aircraft industry. It is necessary to drill boreholes into the parts before they can be connected. However, the individual material components of the stack materials have very different demands with regard to the cutting edge design and optimum process parameters. Apart from that, the quality requirements are very high regarding the reliability of assembly joints [1-3].

\footnotetext{
${ }^{1}$ Institut für Werkzeugmaschinen, Universität Stuttgart, Germany

*E-mail: jonas.duntschew@ifw.uni-stuttgart.de https://doi.org/10.36897/jme/132930
} 
Due to the inhomogeneous, anisotropic texture of the CFRP layer, drilling processes can cause various imperfections on the workpiece, which damage the component. The reject rate of CFRP components due to delamination alone is about $60 \%$ [3]. For that reason, numerous investigations were conducted into the optimization of process parameters and the suitable choice of tool geometry to avoid great damages when drilling stacks [4, 5]. Hocheng showed in his research that the maximum value of feed force should be limited to achieve drilling processes free of delamination [6]. Regarding the drilling of metal layers in stacks, important quality criteria are the geometrical quality accuracy as well as the size of the burr formed. Both factors can have a negative effect on the assembly and the functionality of the components as well as reduce the service life of riveted joints [7].

Abdelhafeez presented in his research an algorithm allowing to correctly predict the burr height in $92 \%$ of cases in a certain range of application for the drilling of titanium-aluminium stacks by means of the measured course of torque [8]. Eynian showed correlations between the wear condition of twist drills and the cutting forces during machining as well as between the burr formation and the surface quality for titanium alloys. As a result, Eynian found out that the feed force and the normal force on the tool nearly quadrupled with progressing wear. Torque, however, increased only by about $70 \%$ with growing wear [8].

Apart from monitoring the forces and torque to assess machining processes, it is also possible to ensure a better understanding of cutting mechanisms by analysing temporal highresolution structure-borne sound signals. Highly dynamic processes can be examined due to the high sampling rates. Navid showed that certain frequency ranges in the structure-borne sound signal could be assigned to the damage mechanisms occurring during the drilling of CFRP. The frequency ranges of $f_{\mathrm{AE}}=0-62.5 \mathrm{kHz}, f_{\mathrm{AE}}=62.5-125 \mathrm{kHz}, f_{\mathrm{AE}}=187.5-$ $250 \mathrm{kHz}$ and $f_{\mathrm{AE}}=312.5-375 \mathrm{kHz}$ was assigned to friction effects, matrix cracks, delamination, and fibre failure [9]. Wang and Lui used this to examine the chip formation effects in high-speed machining of aluminium alloys. Their analyses showed that characteristic frequencies in the acoustic emission (AE) signal could be assigned directly to the geometry of the pattern in the chip root [10]. Furthermore, Arul found out that there was an almost proportional correlation between the wear of the flank face and the root mean square value of structure-borne sound in the drilling of carbon fibre reinforced plastics [11]. In addition, tool wear clearly increased due to the built-up edges on the drill which frequently occur while drilling aluminium alloys [12].

Apart from the cutting processes of the individual stack materials, there are further challenges in drilling of CFRP-aluminium stacks. The different modules of elasticity of the materials and the removal of the often hot metal chips through the CFRP layer cause friction at the drill borehole wall and chip jamming. The accompanying abrasion makes it even more difficult to maintain the diameter tolerances [13]. Moreover, the sharp-edged aluminium chips have a scouring effect on the adhesive layer between the materials [12]. It is possible to improve the drilling process of multimaterial composites by adjusting the process parameters to the demands of the respective material during drilling. This requires to know the exact position of the drill in the material. Neugebauer presented a method, making it possible to identify the transition point between the two materials as well as the entry and exit point of each material in real time during the drilling process by means of structure-borne sound signals and thus to adjust the process parameters to an optimum [15]. 
Previous internal investigations have shown the potentials of analysing the highresolution structure-borne sound signals (AE-Signals) in the burr formation on stacks [16]. It was found out that the quality produced could be deduced from the analysis of AE signals. Furthermore, a correlation of the drill exit AE-signals and the burr formation height has been identified [17].

To proceed the development of the automated quality prediction drilling stack material, this paper follows a wavelet signal analysis approach to realize an automated determination of the delamination of the CFRP layer of the stack material.

\section{EXPERIMENTAL SET-UP}

\subsection{WORKPIECE AND PROCESS SPECIFICATIONS}

The drilling tests were conducted with a MAKA PE 170 5-axis machining centre. The stack workpiece sample consisted of a top layer out of CFRP (fabric mesh with satin weave) and aluminium alloy. The CFRP layer had a thickness of $t_{\text {lay, CFRP }}=4 \mathrm{~mm}$, and the aluminium layer had a thickness of $t_{\text {lay, } \mathrm{Al}}=5 \mathrm{~mm}$. The two layers were joined by an elastomer adhesive layer.

The drilling tests were performed by drilling the CFRP layer first and the exit occurred in the aluminium, see Fig. 1. The structure-borne sounds during drilling were recorded by two high-frequency impulse measurement (HFIM) sensors and then analysed with a QASS Optimizer 4D, see Fig. 1.

HFMI sensor systems are high sensitive measurement devices to detect the mechanical vibrations. It is possible to detect high frequency effects due to the ability of the system to sample signals up to $100 \mathrm{MHz}$. The sensors consist of a highly sensitive oscillating mass. The high resolution of the structure-borne sound signal sensors and the quick real-time data processing of the system made it possible to observe the processes in real time.

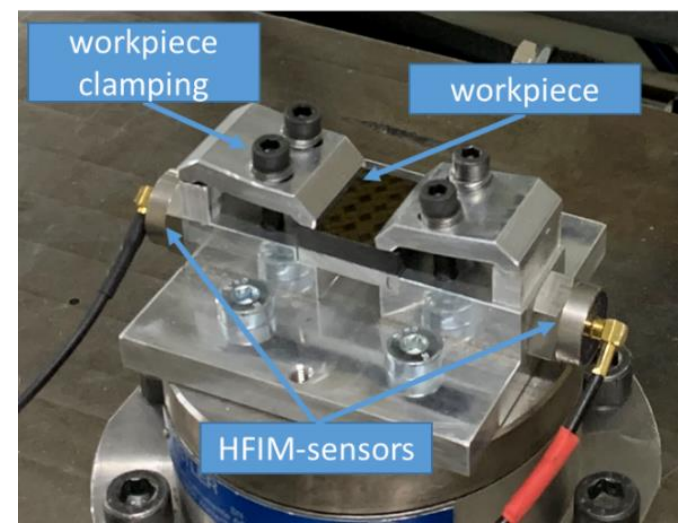

Fig. 1. Experimental Set-up

To realize a signal with no interferences, a symmetrical clamping system was designed and the stack test-pieces were individually processed to perform one drilling operation at each 
test run, see Fig. 1. The drill was positioned to enter the workpiece at the centre of the symmetric clamping system. To achieve comparable results, the test-pieces were fixed with a torque wrench and a defined value.

\subsection{TOOL GEOMETRIES}

Drill geometries with two different point angles were used to create different signals. Preliminary tests (see [16]) have shown that this is a good way to set off the different mechanisms according to Dornfeld [18].

To analyse two different effects in the signal patterns of the emitted structure-borne sound, drills with point angles of $\varepsilon_{1}=105^{\circ}$ and $\varepsilon_{2}=180^{\circ}$ were used in these investigations. The tools and process parameters of the performed experiments are listed in Table 1. The other cutting parameters of the tests were not varied.

Table 1. Tool and process parameters

\begin{tabular}{|l|c|c|c|}
\hline Tool diameter D & $6.4 \mathrm{~mm}$ & Cutting material & Carbide \\
\hline Clearance angle $\alpha$ & $10^{\circ}, 9^{\circ}$ & Point angle $\varepsilon$ & $105^{\circ}, 180^{\circ}$ \\
\hline Rake angle $Y$ & $34^{\circ}$ & Feed per tooth $\mathrm{ft}$ & $0.04 \mathrm{~mm}$ \\
\hline Helix angle $\lambda$ & $30^{\circ}$ & Cutting velocity $v_{c}$ & $101 \mathrm{~m} / \mathrm{min}$ \\
\hline
\end{tabular}

During the drilling experiments a total number of 24 stack test-pieces were drilled, resulting in 12 test-pieces for each tool geometry.

\section{ANALYSIS OF THE AE-SIGNALS AND SURFACE DATA}

\subsection{ACOUSTIC EMISSION SIGNAL WHEN DRILLING STACKS}

The acoustic emission signals of the stack drilling were measured with a sampling rate of $f_{\text {sampl }}=800 \mathrm{kHz}$ to generate a short-time Fourier transformation (STFT) window up to $400 \mathrm{kHz}$. This sample rate was selected based on the results of previous investigations, that showed most signal effects occur below $400 \mathrm{kHz}$ [17].

The different steps of the drilling operation have been divided into six sections as shown in Fig. 2. The first five (tool point entry, drilling of CFRP, passage to aluminium, cutting of aluminium and exit of aluminium) of them were imported to the MATLAB database for further investigations.

Based on these signal sections, the wavelet-analysis has been performed for each drilling step to improve the quality of the results. This signal splitting process was performed for both drill geometries separately to take the different point angles into account. 


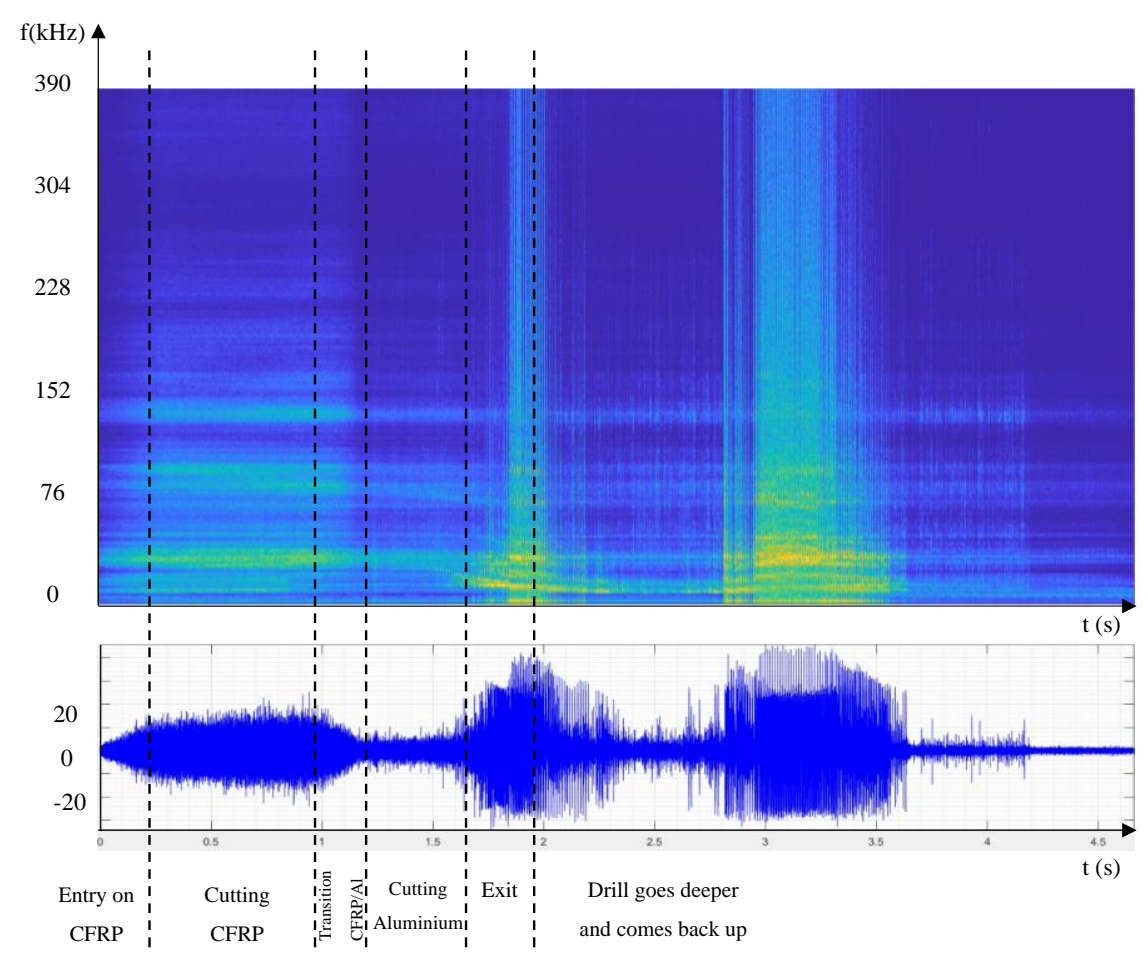

Fig. 2. Spectral analysis for drilling the CFRP/Al stack using the $105^{\circ}$-point-angle drill bit and the selected time intervals

\subsection{ANALYSIS OF THE SURFACE QUALITY (DELAMINATION OF THE CFRP TOP SURFACE)}

To specify a quality index of the CFRP top surface, the delamination of the test-pieces was measured with an Alicona G5 3D microscope. The delamination factor $F_{d}$ is the highest diameter of the occurred delamination $D_{\max }$ in relation to the borehole diameter $D_{\text {norm }}$. The determination of the two diameters is shown in Fig. 3 on the left side as well as the equation of the delamination factor. Additionally, the results of all delamination factors can be found in the two diagrams in Fig. 3.
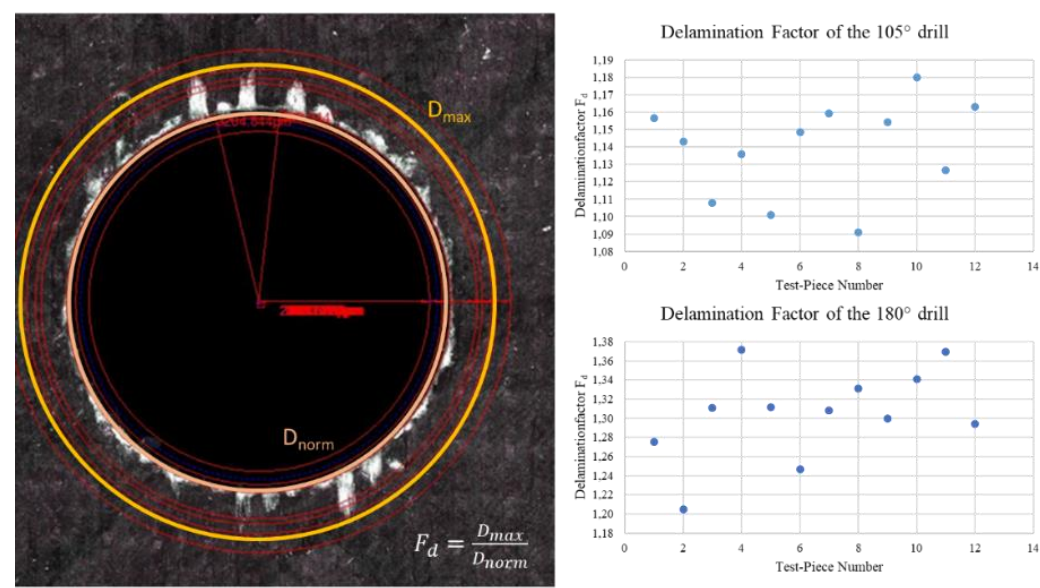

Fig. 3. Example of a borehole top surface image (left) and the delamination factors for all test-pieces 
The delamination measurements show that there is greater delamination with the $180^{\circ}$ point angle and the maximum differences between the highest and lowest delamination is up to twice as much in comparison to the $105^{\circ}$ point angle $(0.17 \mathrm{vs} .0 .09)$.

\section{ANALYSIS OF THE DATA USING WAVELETS}

The discrete wavelet transformation method enables the temporary location of transient events occurring during the monitoring of a cutting process. It transforms a time signal into several independent time-frequency signals called packets. The advantage of the discrete wavelet transformation is its relatively short computing time compared to the continuous wavelet transformation [19]. Fig. 4 shows the analytical procedure of the discrete wavelet transformation method up to the second level and the investigated frequency ranges of the detail information $D_{1-7}$. To obtain an approximated signal $A_{j}$, lowpass filters remove the high frequency fluctuations, while high-pass-filters keep the high frequency signal to provide detailed information $D_{j}$. The characteristic of the high-and low-pass-filters are affected by the wavelet family [20]. There is no further operation performed on the signal $D_{i}$, but the approximation signal is recursively segmented into another approximation signal and detail signal $D_{i+1}$. This procedure is repeated until the desired wavelet decomposition levels are achieved.

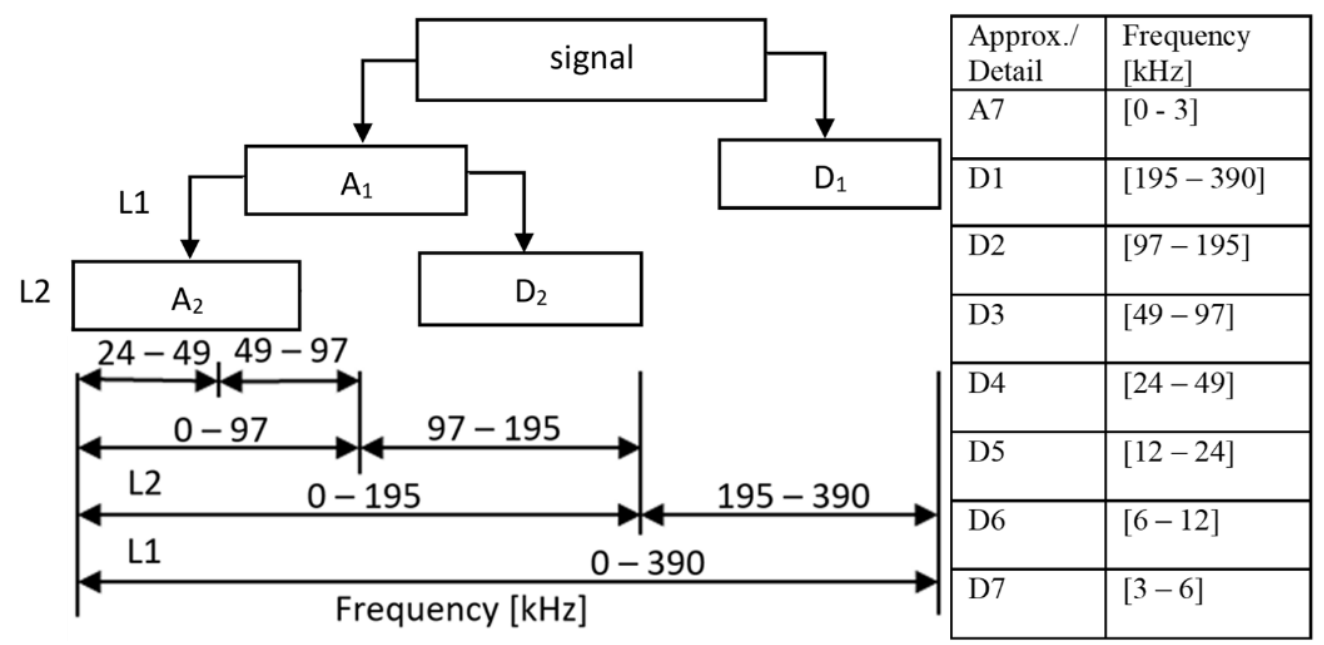

Fig. 4. Wavelet Transformation WT levels and frequency ranges in increasing order on the left, frequency ranges for each detail and approximation component of a 7-level WT on the right

The experimental process contains three main steps: the drilling process including the data acquisition, processing of the data and the evaluation of the results. A more detailed explanation of the procedure is represented by the flowchart in Fig. 5.

To record and process the acoustic emission signal, the QASS Optimizer 4D system was used. The maximum value of delamination was used to calculate the delamination factor $F_{d}$ as presented in Chapter 3. 

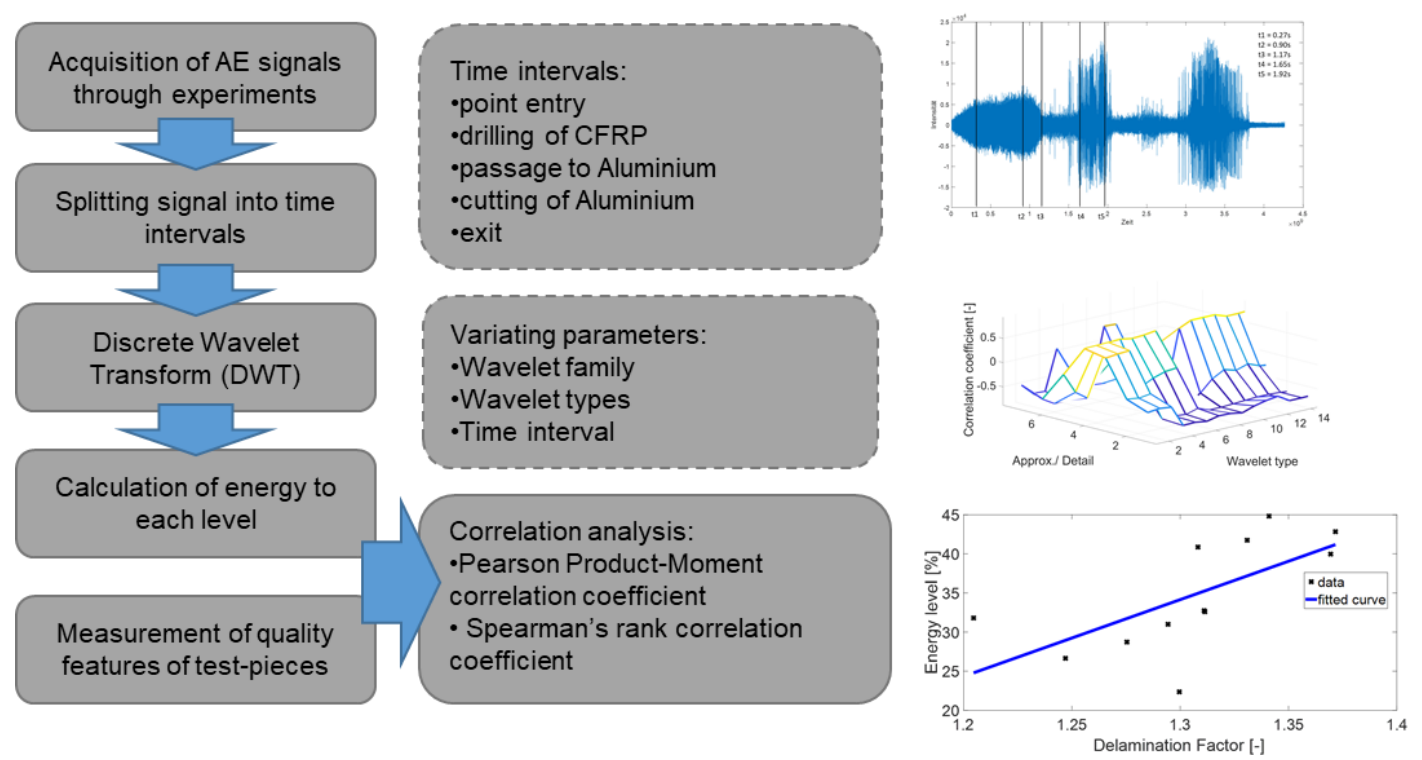

Fig. 5. Flowchart of the signal processing

For further analysis, the raw signal was shortened by defining a threshold and by calculating the machining time. Furthermore, the shortened signal has been split into five sections. Each of these signal sections were converted by using the wavedec function in MATLAB. In this study, the number of levels of the decomposition was set to seven and all available orthogonal or biorthogonal wavelets, as listed in Table 2, were applied.

Table 2. Investigated Wavelet families and types corresponding to orthogonal and biorthogonal wavelets in MATLAB

\begin{tabular}{|c|c|}
\hline Wavelet Families & Wavelets \\
\hline Daubechies & 'db1' or 'haar', 'db2', ..., 'db10', ..., 'db45' \\
\hline Coiflets & 'coif1', ..., 'coif5' \\
\hline Symlets & 'sym2', ..., 'sym8', ...,'sym45' \\
\hline Fejer-Korovkin & 'fk4', 'fk6', 'fk8', 'fk14', 'fk22' \\
\hline Discrete Meyer & 'dmey' \\
\hline Biorthogonal & $\begin{array}{l}\text { 'bior1.1', 'bior1.3', 'bior1.5' } \\
\text { 'bior2.2', 'bior2.4', 'bior2.6', 'bior2.8' } \\
\text { 'bior3.1', 'bior3.3', 'bior3.5', 'bior3.7' } \\
\text { 'bior3.9', 'bior4.4', 'bior5.5', 'bior6.8' }\end{array}$ \\
\hline Reverse Biorthogonal & $\begin{array}{l}\text { 'rbio1.1', 'rbio1.3', 'rbio1.5' } \\
\text { 'rbio2.2', 'rbio2.4', 'rbio2.6', 'rbio2.8' } \\
\text { 'rbio3.1', 'rbio3.3', 'rbio3.5', 'rbio3.7' } \\
\text { 'rbio3.9', 'rbio4.4', 'rbio5.5', 'rbio6.8' }\end{array}$ \\
\hline
\end{tabular}

To generate comparable data of the converted signals, energy values were calculated by using the wenergy function in MATLAB. The results are values of the percentage of energy corresponding to the approximation and the details. The relative wavelet energy can be used as a tool to detect and characterize a specific phenomenon in time and frequency levels [21]. 
In combination with the measurement data of the quality features the correlation analysis has been done, which is described in the following.

\section{CORRELATION BETWEEN WAVELET AND SURFACE DATA}

The two main types of correlation coefficients used are Pearson's Product-Moment correlation coefficient according to the work of Mukaka et al. [22] and Spearman's rank correlation coefficient. The correct usage of the correlation coefficient type depends on the variables being studied. Other types are based on these and are often used when multiple variables are being considered.

Pearson's correlation coefficient is defined as the ratio of the covariance of the two variables to the product of their respective standard deviations. For a population parameter, the moment correlation coefficient is denoted as $\rho$ [22].

$$
\rho=\frac{\operatorname{Cov}(X, Y)}{\sigma_{X} \sigma_{Y}}
$$

By inserting the sample covariance and the sample statistics, the sample coefficient $r$ can be obtained [21].

$$
r=\frac{\sum_{i=1}^{n}\left(x_{i-} \bar{x}\right)\left(y_{i-} \bar{y}\right)}{\sqrt{\sum_{i=1}^{n}\left(x_{i-} \bar{x}\right)^{2}} \sqrt{\sum_{i=1}^{n}\left(y_{i-} \bar{y}\right)^{2}}}
$$

The Pearson's correlation coefficient ranges from -1 to +1 . The absolute value of $\rho$ indicates the strength of the monotonic relationship between the two variables. A positive monotonic association results in $\rho>0$, and a negative monotonic association results in $\rho<0$ [22]. In this case, the variable $x$ represents an array consisting of data of the quality measurement and $y$ represents an array consisting of all the calculated relative wavelet energies.

To give an example for the variations of the Pearson correlation coefficients, Fig. 6 shows a mesh of the Pearson correlation between delamination and wavelet energy using the reverse biorthogonal filter family and drilling with the $180^{\circ}$-point angle drill at the time section of transition between CFRP and Al.

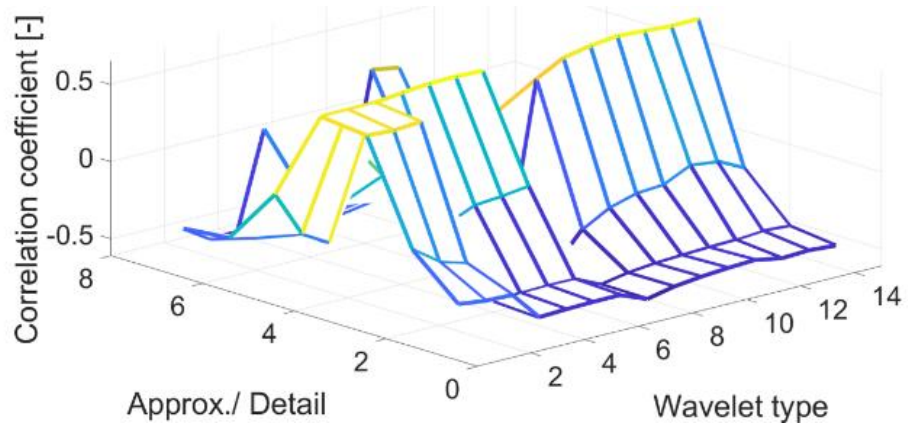

Fig. 6. Pearson correlation between delamination and wavelet energy using the reverse biorthogonal filter and drilling with $180^{\circ}$-point angle at the time interval of transition between CFRP and Al 
The axis called Wavelet type describes the reverse biorthogonal wavelets shown in Fig. 4, where "1" represents "rbio1.1" and "2" represents "rbio1.3" and so on. On the side of the Approx./ Detail-axis, "1" relates to the energy of approximation A7 and "2-8" stand in place for the energies of detail D1-D7, as listed in the Table of Fig. 4.

Facing the fact, that the Pearson correlation evaluate only the linear correlation the investigation is extended by the Spearman rank correlation to evaluate the monotonic relationship.

Table 3. Highest correlation factors for each wavelet family

\begin{tabular}{|l|c|c|c|c|c|c|c|c|}
\hline \multicolumn{9}{|c|}{$180^{\circ}$-point angle } \\
\hline Filter family & $\begin{array}{c}\text { Pearson correlation } \\
\begin{array}{c}\text { Correlatio } \\
\text { n factor }\end{array}\end{array}$ & $\begin{array}{c}\text { Approx./ } \\
\text { Detail }\end{array}$ & $\begin{array}{c}\text { Wavelet } \\
\text { type }\end{array}$ & $\begin{array}{c}\text { Time } \\
\text { Interval }\end{array}$ & $\begin{array}{c}\text { Spearman } \\
\text { Correlation } \\
\text { factor }\end{array}$ & $\begin{array}{c}\text { Approx./ } \\
\text { Detail }\end{array}$ & $\begin{array}{c}\text { Wavelet } \\
\text { type }\end{array}$ & $\begin{array}{c}\text { Time } \\
\text { Interval }\end{array}$ \\
\hline Biorthogonal & 0.6529 & D5 & 12 & 3 & 0.7902 & D5 & 12 & 3 \\
\hline Coiflets & 0.6310 & D5 & 2 & 3 & 0.7413 & D5 & 2 & 3 \\
\hline Daubechies & 0.6341 & D5 & 6 & 3 & 0.7622 & D4 & 1 & 2 \\
\hline Discrete Meyer & 0.5943 & D5 & 1 & 3 & 0.6783 & D5 & 1 & 3 \\
\hline Fejer-Korovkin & 0.6278 & D5 & 3 & 3 & 0.7692 & D4 & 1 & 2 \\
\hline $\begin{array}{l}\text { Reverse } \\
\text { Biorthogonal }\end{array}$ & 0.6332 & D4 & 9 & 3 & 0.7692 & D4 & 9 & 2 \\
\hline Symlets & 0.5328 & D5 & 9 & 3 & 0.6140 & D5 & 3 & 3 \\
\hline
\end{tabular}

To find the best correlation between quality feature and wavelet energy, the maximum value of all correlation coefficients must be determined. Table 3 presents the best correlation scenario and their configuration for each wavelet family. To understand the amount of the performed calculations for each wavelet family, Fig. 6 can be regarded as one of five (because of the different time intervals) calculations to represent the total correlation of one wavelet family.

Considering delamination, the highest correlation of either Pearson or Spearman appeared in the time section of the transition between CFRP and Al usage of the reverse biorthogonal filter "rbio2.4" of detail D12. The calculated correlation factor is 0.653 for Pearson and 0.79 for Spearman. Figure 7 shows the graph of delamination in comparison to the evolution of the energy level using the reverse biorthogonal filter "rbio2.4" in detail D12 for the $180^{\circ}$-point angle.

The best correlating results of the $105^{\circ}$ point angle drill are 0.57 using Pearson and 0.63 with Spearman. Both using the biorthogonal filter family "rbio2.4". Regarding this result, the biorthogonal filter presents the best correlation for both tool geometries.

To evaluate the linear behaviour a fitted linear curve has been added, with a calculated root-mean-square deviation of 0.57. It can be seen that the results in Fig. 7 show a good correlation between the calculated energy level and the delamination factor for most of the energy levels. But the fact must be faced, that one wavelet family alone can't image all occurring effects of such a highly inhomogeneous process. Those deviations can be caused by signal interferences or inconsistent cutting conditions of the CFRP layers, such as matrix cracking and other statistical appearing effects. A manual investigation of the documented 
CFRP surface quality has not led to a visual understanding of the deviant energy level behaviour calculated by the chosen wavelet family for some test-pieces in Fig. 7.

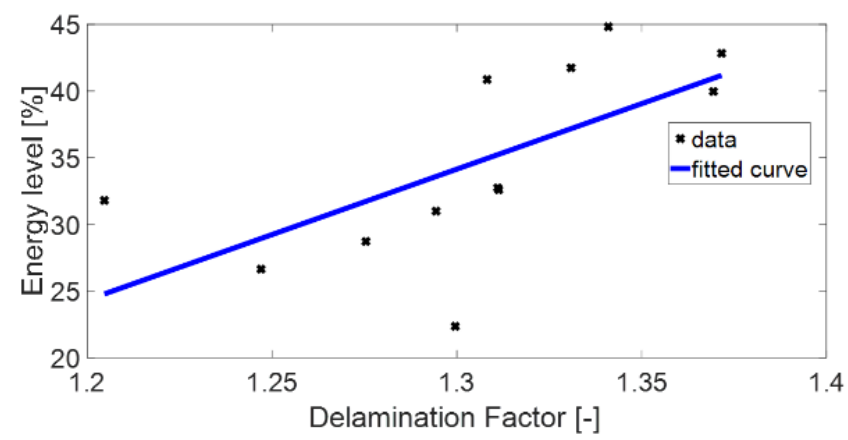

Fig. 7. Graph of delamination and wavelet energy of "rbio2.3" in detail D12 for $180^{\circ}$-point angle

In order to improve the correlation, the combination of different wavelet filters has to be investigated in further research work.

\section{CONCLUSION}

The presented investigation showed the capability of the discrete wavelet transformation regarding the determination of the surface quality at drilling operations of CFRP-AluminiumStack material. Several wavelet families and types have been tested to identify the best approach.

Due to the highly inhomogeneous material it was not possible to find a perfect correlation. Nevertheless, the wavelet results for the $180^{\circ}$-point angle drill showed a Pearson correlation of 0.65 and spearman correlation of 0.79 when using a reverse biorthogonal filter. During the analysis of the $105^{\circ}$-point angle drill data, a maximum correlation of 0.63 was achieved.

This paper gives an overview of the common wavelet filters and how their performance regarding the prediction of delamination effect is.

Further investigation will study how other quality criteria of stack-material such as the burr height, cylindricity and fibre pull outs can be analysed by algorithms based on the processing of acoustic emission signals. Moreover, the possibilities of a combined processing algorithm to evaluate several wavelets will be tested to improve the correlation results. In this context the implementation of a multi-layer wavelet processing of the acoustic emission signals will be investigated to take several cutting effects and signal deviations into account.

\section{REFERENCES}

[1] STUHRMANN J., 2016, Herausforderungen beim Bohren von CFK und CFK-Mischverbunden beim Airbus A350XWB, 6. IfW-Tagung. Bearbeitung von Verbundwerkstoffen - Spanende Bearbeitung von CFK, Stuttgart.

[2] TETI R., 2002, Machining of Composite Materials, CIRP Annals, 51/2, 611-634.

[3] FlEISCHER J., TETI R., LANZA G., MATIVENGA P., MÖHRING H.C. Caggiano A., 2018, Composite Materials Parts Manufacturing, CIRP Annals - Manufacturing Technology, 67, 603-626. 
[4] LIU D., TANG Y., CONG W.L., 2012, A Review of Mechanical Drilling for Composite Laminates, Composite Structures, 94/4, 1265-1279.

[5] E-mobil BW GmbH, 2012, Fraunhofer Institut für Produktionstechnik und Automatisierung: Spanende Bearbeitung von Leichtbauwerkstoffen, Mühlacker, Karl Elser Druck GmbH.

[6] HOCHENG H., TSAO C.C., 2005, The Path Towards Delamination-Free Drilling of Composite Materials, Journal of Materials Processing Technology, 167/2-3, 251-264.

[7] ABDELHAFEEZ A.M., SOO S.L., ASPINWALL D.K., DOWSON A., ARNOLD D., 2015, Burr Formation and Hole Quality when Drilling Titanium and Aluminium Alloys, Procedia CIRP, 37, 230-235.

[8] EYNIAN M., DAS K., WRETLAND A., 2017, Effect of Tool Wear on Quality in Drilling of Titanium Alloy Ti6Al4V, Part I: Cutting Forces, Burr Formation, Surface Quality and Defects, High Speed Machining, 3/1, 1-10.

[9] NAVID Z.K., GIANGIACOMO M., PARNIAN K., 2015, Analysis of Damage Mechanisms in Drilling of Composite Materials by Acoustic Emission, Composite Structures, 131, 107-114.

[10] WANG B., LIU Z., 2017, Acoustic Emission Signal Analysis During Chip Formation Process in High Speed Machining of 7050-T7451 Aluminum Alloy and Inconel 718 Superalloy, Journal of Manufacturing Processes, 27, $114-125$.

[11] ARUL S., VIJAYARAGHAVAN L., MALHOTRA S.K., 2007, Online Monitoring of Acoustic Emission for Quality Control in Drilling of Polymeric Composites, Journal of Materials Processing Technology, 185/1-3, 184190.

[12] ZITOUNE R., KRISHNARAJ V., COLlOMBET F., 2010, Study of Drilling of Composite Material and Aluminium Stack, Composite Structures, 92/5, 1246-1255.

[13] GÜZEL K., TALPEANU D., KIMMELMANN M., MÖHRING H.C., 2018, Potentiale in der Bohrbearbeitung von CFK-Aluminium-Stacks mit plasmageschärften Bohrwerkzeugen, wt Werktstattstechnik online, 1/2, 67-73.

[14] BRINKSMEIER E., JANSSEN R., 2002, Drilling of Multi-Layer Composite Materials Consisting of Carbon Fiber Reinforced Plastics (CFRP), Titanium and Aluminum Alloys, CIRP Annals, 51/1, 87-90.

[15] NEUGEBAUER R., BEN-HANAN U., IHLENFELDT S., WABNER M., STOLL A., 2012, Acoustic Emission As a Tool for Identifying Drill Position in Fiber-Reinforced Plastic and Aluminum Stacks, International Journal of Machine Tools and Manufacture, 57, 20-26.

[16] MÖHRING H.C., KIMMELMANN M., ESCHELBACHER S., GÜZEL K., GAUGGEL C., 2018, Process Monitoring on Drilling Fiber-Reinforced Plastics and Aluminum Stacks Using Acoustic Emissions, 18th Machining Innovations Conference for Aerospace Industry, Procedia Manufacturing, 18, 58-67.

[17] MÖHRING H.C., KIMMELMANN M., DUNTSCHEW J., SCHLUCHTER I., 2019, Analysis of Burr Formation Mechanisms When Drilling CFRP-Aluminium Stacks Using Acoustic Emission, 19th Machining Innovations Conference for Aerospace Industry, Procedia Manufacturing, 40, 64-69.

[18] DORNFELD D., 1994, In Process Recognition of Cutting States, JSME International Journal, Ser. C, Dynamics, Control, Robotics, Design and Manufacturing, 37/4, 638-650.

[19] GAU R.X., YAN R., 2011, Wavelets, Theory and Applications for Manufacturing, Springer, New York.

[20] GARCÍA PLAZA E., NÚÑ̃Z LÓPEZ P.J., 2019, Application of the Wavelet Packet Transform to Vibration Signals for Surface Roughness Monitoring in CNC Turning Operations, Mechanical Systems and Signal Processing, 98, 902-919.

[21] SALWANI M.D., JASMY Y., 2005, Relative Wavelet Energy As a Tool to Select Suitable Wavelet for Artefact Removal in EEG, 1 st International Conference on Computers, Communications \& Signal Processing with Special Track on Biomedical Engineering, Kuala Lumpur, Malaysia, 282-287.

[22] MUKAKA M.M., 2012, A Guide to Appropriate Use of Correlation Coefficient in Medical Research, The Journal of Medical Association of Malawi, 24, 69-71. 